\title{
School Centered Evidence Based Accountability
}

\author{
Charles Milligan \\ College of Education, Middle Tennessee State University, USA
}

Copyright (C) 2015 by authors, all rights reserved. Authors agree that this article remains permanently open access under the terms of the Creative Commons Attribution License 4.0 International License

\begin{abstract}
Achievement scores drive much of the effort in today's accountability system, however, there is much more that occurs in every school, every day. School Centered Evidence Based Accountability can be used from micro to macro giving School Boards and Administration a process for monitoring the results of the entire school operation effectively and efficiently. All aspects of the school community can and should be incorporated including district, state and federal requirements. This is an all-inclusive process. After leading the community in setting the vision and mission, the School Board can use one process to capture the entire efforts of the school community providing a comprehensive view of the "State of the School". Maximize your time and efforts by using a systematic approach to review (1) teaching and learning, (2) safety, (3) allocation of resources and (4) communication.
\end{abstract}

Keywords Accountability, Assessment, Planning, Improvement

\section{Introduction}

As our world changes around us, the education system that we work within must also adapt to a technological global future. No one disagrees that educators are faced today with increasing pressure from all sectors of our society to improve. With Federal initiatives like Race to the Top and No Child Left Behind, "being accountable" is not just a phrase discussed in the nation's school districts evaluation offices but is now a part of every level of education. Seeing change in the air, former NEA president Reg Weaver [2008] told audiences around the country that long-term solutions, risk-taking, innovation, and the ability to change and meet new challenges were key to the nation's economic future [Walker, 2008]. Whether we agree with the current drive for accountability or not, one thing is certain, we must fundamentally change the way we do business. Accountability is no longer "optional" but a necessary component of school improvement.

With ever increasing requirements and diminishing budgets, principals today require new techniques to not only attain success in academic achievement but also in student and staff safety, allocation of resources and high quality, targeted professional development to all staff members. There is still only 24 hours in a day, with no seemingly end to the ways you receive information, and time is critical factor in any program for success. To really improve administrators need to maximize their efforts and time by using a systematic approach to accountability, spending your time on monitoring and improving, not regulating!

It would seem to make sense that it is necessary to develop a model that not only was inclusive of the quantitative data of test scores, attendance and safety incidences but also included the qualitative data of classroom innovations, school climate and community relations. Even comprehensive reviews of accountability models admit that: "In today's high-stakes accountability world, we are often forced to implement new methodologies before the value of such methodologies can be fully understood" [Dunn, Allen 2009]. Schools do much more than prepare students to take tests. We must be careful when we attempt to capture the essence of education. As Rapple [1994] noted, "True accountability in education should not be facilely linked to mechanical examination results, for there is a very distinct danger that the pedagogical methods employed to attain those results will themselves be mechanical and the education of children will be so much the worse". [p. 21]. Even school psychologist seem opposed to testing accountability models, sighting that these models are more goal orientation theory that actually achievement [Anderman, Anderman, Yough, and Gimbert 2010]. Agreeing that is takes more than just test scores to improve student learning is perhaps the solidifying point. It takes more; it takes leadership and community support [Firestone 2009]. School Centered Evidence Based Accountability, as a whole system (or whole school) process approach, will capture the quintessence of testing data, and allow for the inclusion of qualitative data as well.

\section{The Model}

While the concept of school accountability is not a new issue, the contiguous elements that includes planning, 
communication, and evaluation/modification are not. School Centered Evidence Based Accountability (SCEBA) is not an event but a process. When it is applied to the whole school atmosphere a coherent systematic model is developed. Schools typically develop a plan that remains within the school, never involving the parents, students and the greater community in the communication loop. Most communication models deal with the internal communication of the various school affiliated stakeholders [Bauer and Bogotch, 2006] with little thought to the greater community. Blending communication as an equal partner with problem analysis and evaluation is the uniqueness of School Center Evidence Based Accountability.

The defining principle of the SCEBA is "prove it". There are three phases (Planning, Commitment and Focus) with seven procedural steps. Planning Phase

- Identify the problem

- Develop the plan

1. Commitment Phase

- Commit the stakeholders

- Communicate the goals

2. Focus Phase

- Monitor the Implementation

- Measure the Progress

- Modify the plan if you are not making adequate progress

\section{Phase 1}

Identify the Problem. Nothing can really happen if you have not identified your problem areas. While there can be much discussion about what are priorities, it seems reasonable to assume that most schooling functions fall into five categories: Learning, safety, training, community and resources. The planning begins with a critical analysis of each category to develop goals statements for each of the five school function categories. For this portion, PTA Officers, Site Council Leaders, Department or Grade Level Leaders and if appropriate student leaders should work together with administration to craft the language of the goal statement. The statements work best if they are limited to one sentence. These goals become the corner stone of Phase 2 .

The school leader now is ready to begin classifying the problem by conducting a strategy with an expanded group of school stakeholder (perhaps 50). Plan a whole day for this phase, making an event of the process. Many different strategies can be used but it is important to discuss what the school stakeholder feel they are going well. Guide the discussion using the five categories. It is particular effective to have an outside facilitator familiar with Strategy Planning to assist in this discussion. Still focusing on the five categories, the discussion progresses to identify what you are not doing well. Make lists under each of the five goals. Continue until saturation and redundancy begins to occur. Break for lunch and let the group absorb the lists of areas for improvement. Your last step in the process is to give everyone five colored dots and ask them to put a dot by the ones that they believe should be a priority. At the conclusion you will have a graphic depiction of what your school stakeholders believe are the priority problems. Using all the school stakeholders to help identify the problem areas is a wise decision as it will help in Phase two.

Develop the plan. Whether it is the district or a school creating the plan is an important step. Each department and school should now use the 5 Goal Areas and develop strategies targeted towards the improvement of the problems identified. Essential in the strategy statement is the responsible party, what resources are needed, when it will be completed and what is the evidence that the strategy was effective. The plan should include all grant, state and federal requirements. All departments and schools should develop a plan for success. All groups participating in the schools should also complete a plan with the PTA/PTO actually having a portion of the school plan as their own.

\section{Phase 2}

Commit the stakeholders. When the plan is completed meet again with the stakeholders that helped to develop the plan. Go through a process to review the plan. Insure that there is an understanding of what the plan contains and go through a formal adoption process. Conduct several school meeting and present the plan. It helps to have the room adorned with the pages of prioritization so that the community understands the process.

Communicate the goals. Create posters with the five goals displayed and ask the local merchants to post in their businesses. You will be surprised at how many will be willing to participate in the process. Have business size cards printed and ask your staff to carry the goals as well as your stakeholders. In all expenditure, identify the exact goal number that is supported by the dollars. Have bumper stickers printed and give out at fundraisers and assemblies. Ask the local theater to run the goals in between movie showings as a public service announcement. The bottom line is that every occasion you have to communicate the goals take the opportunity with enthusiasm.

\section{Phase 3}

Monitor the Implementation. The plan must become a living document that is continually reviewed and even updated. A yearly achievement calendar should be maintained. There are many software products that manage these tasks automatically or you can just make a calendar, noting times when certain mile stones are to be reached. Weekly, complete a simple one page report that reports the happening of the department or school. Ask your department chairs to help you complete the report by supplying you with one statement, aligned to the goal, which reports any progress made. Always begin with the goal number identified. Remember whatever isn't monitored, doesn't get done and remember key in the process is evidence. How are you best seizing the essence of what is being done. Build a portfolio of evidence as you go along. When you get to the end of the year, you will be amazed at what you have done 
and now you have proof. District reports can be complied and given as a Board Report for weekly progress. If weekly seems too aggressive, two will work but no longer timeframe should elapse.

Measure the Progress. As the year progresses, compile a simple graph delineating what the departments/schools have reported by goals. It is very easy to see where you are spending your time with some type of graphic display. If one school seems to spend all their time in student safety, training and community with very little in learning, there is always time to re-center and focus. Or more importantly reallocate resources. Reporting for grants state and federal requirements becomes easier as all the information complete with timelines and responsible parties have already been documented. It becomes a simple task to compile the information necessary.

Modify The Plan If You Are Not Making Adequate Progress. As you near completion of the year it is important to insure that you have completed all tasks. As the new school year begins you will bring together your school stakeholders and review the past year. Again, display the previous year's problem identification material and start the process again. Determine if you indeed accomplished what you defined as the issue. It is now appropriate to discuss roadblocks that always occur in any process and determine if they in fact deserve their own repair strategy. This brings you back to the start of the SCEBA process.

\section{Conclusions}

Achievement scores drive much of the effort in today's accountability system, however, there is much more that occurs in every school, every day. School Centered Evidence Based Accountability can be used from micro to macro giving School Boards and Administration a process for monitoring the results of the entire school operation effectively and efficiently. Accountability is change for many school systems and "the only one who truly likes change is a wet baby" [Tate, 2004]. Most improvement system, no matter how commonsensical the approach, is organizational change and the leader must insure that all school stakeholders understand the process and have an understanding of expectations [Caillier, 2010]. As educators struggle as to how to best capture what a school is accomplishing, artifacts in addition to test scores as evidence would seem to be the paramount to demonstrate improvement. Although test scores are essential, remember,
"Not everything that can be counted counts, and not everything that counts can be counted" [Einstein, attributed]. School Centered Evidence Based Accountability can be used from micro to macro; giving administrators a process for accountability, from development of improvement plans to monitoring results, effectively and efficiently.

\section{REFERENCES}

[1] Anderman, Eric, Anderman, Lynley, Yough, Michael and Gimbert, Belinda [2010], Value-Added Models of Assessment: Implications for Motivation and Accountability, Educational Psychologist, 45[2], 123-137, 2010.

[2] Scott C. Bauer and Ira E. Bogotch [2006], Journal of Educational Administration, Vol. 44 No. 5, pp. 446-470, Emerald Group Publishing Limited.

[3] Caillier, James, [2010], Paying Teachers According To Student Achievement: Questions Regarding

Pay-For-Performance Models in Public Education, The Clearing House, 83: 58-61.

[4] Dunn, Jennifer, Allen, Jessica, [2009], Holding Schools Accountable for the Growth of Non-proficient Students: Coordinating Measurement and Accountability, Educational Measurement: Issues and Practice Winter 2009, Vol. 28, No. 4, p 40

[5] Einstein, Albert, [Attributed], [1879 - 1955], [internet] Available from: http://www.quotationspage.com/quote/2695 0.html, [cited 2014 Dec 10].

[6] Firestone, William [2009], Accountability Nudges Districts into Changes in Culture, PHI Delta Kappan, May 2009, p. 671 .

[7] Rapple, B. A.[1994], Payment by results: An example of assessment in elementary education from nineteenth century Britain. [internet] Education Policy Analysis Archives, 2[1], [cited 2014 Dec 13]. Available from http://epaa.asu.edu/ojs/article/view/664

[8] Tate, Marcia, [2004] "Sit and Get" Won't Grow Dendrites, 20 Professional Learning Strategies That Engage the Adult Brain, Corwin Press, A Sage Publishing Company, Thousand Oaks, CA.

[9] Walker, Tim [2008], [internet] Preparing Our Schools for Tomorrow's World, March, NEA Today [cited 2014 Dec 14]. Available from: http://www.nea.org/home/4213.htm 